\title{
The Study of Consumer Purchase and Forward Intention in WeChat E-Commerce Marketing
}

\author{
Jia-Jia MENG ${ }^{1,2,3}$ and Wen-Jun LIU ${ }^{4, *}$ \\ ${ }^{1}$ Postdoctoral Programme, China Business Executives Academy, Dalian, No. 777, \\ Hongling Road, High-Tech District, Dalian, China \\ ${ }^{2}$ Postdoctoral Programme, Tsinghua University School of Economics and \\ Management, Haidian District, Beijing, China \\ ${ }^{3}$ SWIBS, Liaoning University, No. 58, South Daoyi Road, Shenyang, China \\ ${ }^{4}$ School of Management and Economics Dalian University of Technology, No. 2, \\ Linggong Road, Dalian, China \\ ${ }^{*}$ Corresponding author
}

Keywords: E-Commerce, WeChat marketing, Relationship intensity, Brand image, Purchase intention, Forward intention.

\begin{abstract}
In the context of Wechat marketing, this study investigated antecedents and boundary conditions of consumer purchase and forward intention. The results indicated relationship intensity, brand image and dispositional trust have positive effect on consumer purchase and forward intention; the effects are moderated by product price and type. When the price increased, the relationship between brand image and purchase intention is weaken, but the relationship between brand image and forward intention is strengthen, the relationship between dispositional trust and forward intention is weaken. For the search good, brand image is the critical factor for consumer purchase and forward; but for the experience good, relationship intensity is much more important.
\end{abstract}

\section{Introduction}

The rapid development of mobile internet technology, led to the changes of consumer social and buying behavior. Since 2011, Tencent launched mobile social APP WeChat, which conducted a social platform based on the acquaintance circles. By the end of 2015, WeChat monthly active users has reached 697 million, and the consumption scale breaks through 11 billion RMB which directly driven by WeChat. It has become the important social media marketing platform. When the "friends circle" encounters "business", what will happen? This study investigates antecedents and boundary conditions of consumer purchase and forward intention in WeChat. It will provide theoretical and practical support for the further development of mobile marketing.

\section{Literature Review and Research Model}

WeChat marketing is an approach that the sellers communicate the product and service information with the target consumers through WeChat. Current researches focus on how firms use WeChat to carry out marketing activities. Due to the commercial value of WeChat, individual e-commerce sprung up in the WeChat friends circle, based on the relationship between acquaintances. Compare to enterprise official account, individual e-commerce sellers are much more close to their friends which are the potential 
consumers, and they can use the WeChat moments and friend groups as the main way to share product and service information, and also conduct the real-time interaction.

Relationship intensity represents the overall evaluation of the relationship between two individuals, including interactive frequency, intimacy degree, reciprocal content and time duration [1]. The strong relationship groups are more likely to communicate feelings and information, and is thought to be reliable, the word of mouth effect is significantly greater than the weak relationship groups. Studies from virtual community indicate that the relationship intensity of information receiver and sender has a positive effect on purchase intention and recommendation [2]. Zhou (2012) put forward and tested the informational social influence on behavioral intention from strong relationship group is greater than the weak group [3]. On this basis, we proposed:

H1a: Relationship intensity has positive effect on purchase intention;

$\mathrm{H} 1$ b: Relationship intensity has positive effect on forward intention.

Brand image is the consequence of consumer stereotypes for the target brand and individualized information processing [4]. Consumers will be also affected by brand image during the information dissemination and sharing process, Chen (2013) tested the positive relation between online word of mouth and brand image through the study of clothing brand [5]. On this basis, we proposed:

$\mathrm{H} 2 \mathrm{a}$ : Brand image has positive effect on purchase intention in WeChat marketing;

$\mathrm{H} 2 \mathrm{~b}$ : Brand image has positive effect on forward intention in WeChat marketing.

WeChat marketing is based on trust. As a result, consumer's individual trust propensity will affect the formation of purchase intention. Individual trust propensity is a universal dependent willingness based on the extension of social dependence on others, which is the implicit characteristic and will not easily change with the external environment. In the e-commerce situation, consumer's individual trust propensity will reduce the perceived risk of online shopping [6], and will also influence consumer's willingness to share and purchase [7]. On this basis, we proposed as following:

$\mathrm{H} 3 \mathrm{a}$ : Individual trust propensity has positive effect on purchase intention;

H3b: Individual trust propensity has positive effect on forward intention.

Product price represents the monetary value. According to the Elaboration Likelihood Model (ELM) [8], we suggest that in the WeChat marketing, for the high-priced products, consumers will be more rational when they make the purchase and forward decisions, and more consider the brand as a product evaluation clues; for the low-priced products, consumers will choose peripheral route, link the product and emotional attitudes. On this basis, we proposed:

H4a: Price negatively moderate effect of relationship intensity on purchase intention;

H4b: Price negatively moderate effect of relationship intensity on forward intention;

H4c: Price positively moderate effect of brand image on purchase intention;

$\mathrm{H} 4 \mathrm{~d}$ : Price positively moderate effect of brand image on forward intention;

H4e: Price negatively moderate effect of trust propensity on purchase intention;

H4f: Price negatively moderate effect of trust propensity on forward intention;

For search good, consumers can easily acquire the properties of product related information before purchase, such as price, quality, performance, etc.; for experience good, consumers can learn about relevant attribute information of product or service after trial. Under e-commerce environment, the product type moderates the effect of social factors and brand image on the purchase attitude [9].Therefore, we proposed:

H5a: For search good, brand image has more effect on purchase intention;

H5b: For search good, brand image has more effect on forward intention;

H5c: For experience good, relation intensity has more effect on purchase intention; 
H5d: For experience good, relation intensity has more effect on forward intention; Based on above analysis, we construct the research model which is shown in figure 1:

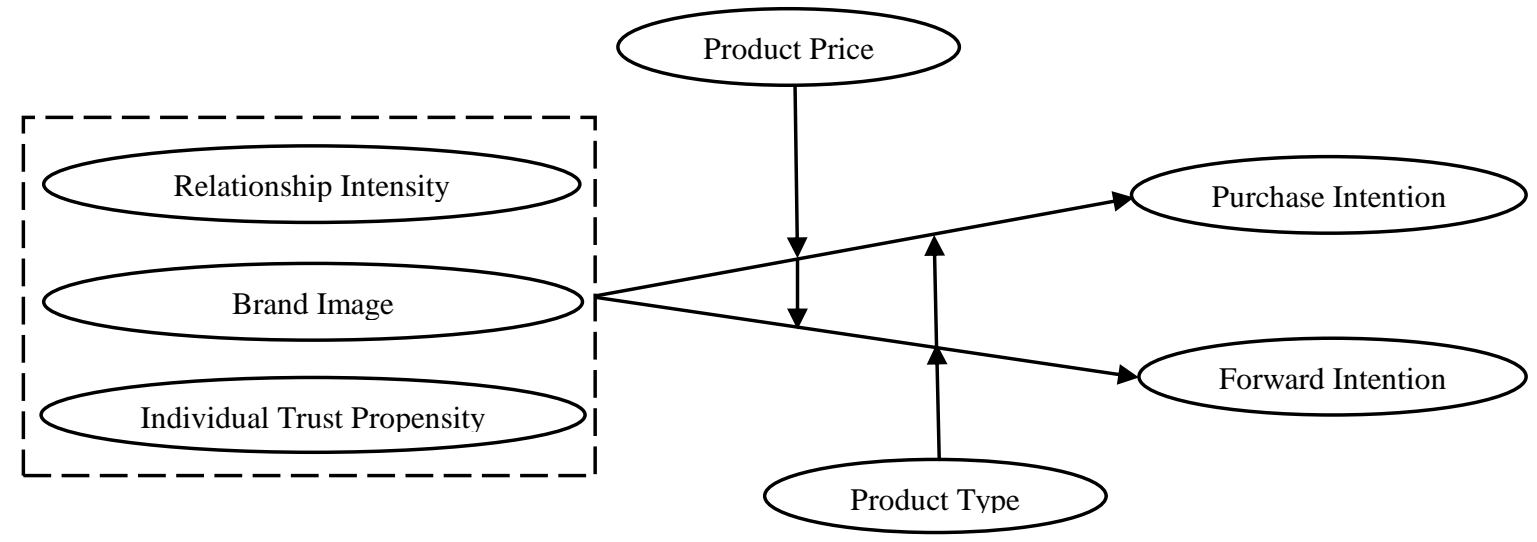

Fig. 1 The research model of the study

\section{Research Design}

\section{Data Collection}

Data used in the study were obtained through questionnaire survey from WeChat users. On the basis of literature review and consumers qualitative interviews, we designed the initial questionnaire, and modified through preliminary investigation, forming a formal questionnaire. We tried to employ the mature scales which used in the former literatures to ensure the reliability and validity. We measured the relationship intensity with 4 items, brand image with 3 items, individual trust propensity with 4 items, purchase intention with 4 items and forward intention with 2 items. We measured all constructs on 7 Likert scales (from significantly disagree to significantly agree) except the product price and type with open questions which are divided into 7 price level and 2 product types after data collection. We collected data through multi channels including online system, QQ and WeChat links and finally received 193 responses, we got 170 valid samples. This constituted $88.08 \%$ response rate. We also examined the sample and nonresponsive bias. The result presented no significant bias in the study.

\section{Reliability and Validity of the Scales}

In the Exploratory Factor Analysis, we perform all items for factor analysis through the principal component factor analysis with varimax rotation. The result passed the KMO and Bartlett's Test $(\mathrm{KMO}=0.872)$ and indicated 5 factors in Tab. 1 , accumulative total variance explained at a rate of $76.749 \%$. The loadings are all above the standard of 0.50 and no cross factor loading. It proved the measure of the scales is logical.

Tab. 1 Reliability and Validity Analysis of Each Variable

\begin{tabular}{|c|c|c|c|}
\hline Variable & $\begin{array}{c}\text { Factor } \\
\text { loading }\end{array}$ & CITC & $\begin{array}{c}\text { Cronbach } \\
\alpha\end{array}$ \\
\hline Relationship Intensity & $0.64 \sim 0.88$ & $0.64 \sim 0.85$ & 0.910 \\
\hline Brand Image & $0.89 \sim 0.92$ & $0.87 \sim 0.90$ & 0.946 \\
\hline Individual Trust Propensity & $0.77 \sim 0.83$ & $0.62 \sim 0.70$ & 0.834 \\
\hline Purchase Intention & $0.79 \sim 0.83$ & $0.72 \sim 0.85$ & 0.900 \\
\hline Forward Intention & $0.77 \sim 0.83$ & $0.59 \sim 0.59$ & 0.745 \\
\hline
\end{tabular}


To test the reliability, a combination of Correlated Item-to-Total Correlations and Cronbach Alpha was used. As it can be seen in Tab. 1, all constructs have Cronbach Alphas that range between 0.745 and 0.946 , indicating significant acceptable levels of reliability (Nunally 1978). Moreover, the values of CITC are all above 0.5 , and delete any item can't improve the Cronbach Alphas for every construct. The results indicated that the scales were unidimensional.

\section{Results}

We tested hypotheses by multiple regression analysis. The results are shown in Tab. 2 4. As showed in Tab. 2, relationship intensity $(\beta=0.424, P<0.001)$, brand image $(\beta=0.340, \mathrm{P}<0.001)$, individual trust $\operatorname{propensity}(\beta=0.172, \mathrm{P}<0.001)$ had a significant positive effect on purchase intention; the relationship intensity $(\beta=0.169, \mathrm{P}<0.001)$, the brand image $(\beta=0.299, \mathrm{P}<0.001)$, Individual Trust Propensity $(\beta=0.119, \mathrm{P}<0.1)$ had a significant positive effect on forward intention, H1a H3b are supported.

Tab. 2 Results for Main Effects

\begin{tabular}{|c|c|c|}
\hline & \multicolumn{2}{|c|}{ DV } \\
\hline IV & Purchase Intention & Forward Intention \\
\hline Relationship Intensity & $.424^{* * * *}$ & $.169^{* * *}$ \\
\hline Brand Image & $.340^{* * *}$ & $.299^{* * *}$ \\
\hline Individual Trust Propensity & $.172^{* * *}$ & $.119^{\dagger}$ \\
\hline $\mathrm{R}^{2}$ & .442 & .272 \\
\hline Adjusted R & .259 \\
\hline $\mathrm{F}$ & .432 & $20.706^{* * *}$ \\
\hline \multicolumn{2}{|c}{$\mathrm{p}^{2}<0.05^{* * \mathrm{p}}<0.01 * * * \mathrm{p}<0.001$} & \\
\hline
\end{tabular}

The moderator effects of price are shown in Tab. 3. Because the price is continuous variable, we construct the product term to test the moderator effect, and before the construction, we centralized processing variables in advance. As showed in Tab. 3, the product term of brand image and price had significant influence on forward intention $(\beta=0.348, \mathrm{P}<0.001)$; the product term of individual trust propensity and price had significant influence on forward intention $(\beta=-0.464, \mathrm{P}<0.001)$, and the effects of other product terms are not significant, $\mathrm{H} 4 \mathrm{~d}$ and $\mathrm{H} 4 \mathrm{f}$ are supported, $\mathrm{H} 4 \mathrm{c}$ is contrary to our hypothesis, the other hypotheses are not support.

Tab. 3 Results for Moderator Effects of Price

\begin{tabular}{|c|c|c|c|c|c|c|}
\hline & \multicolumn{2}{|c|}{ DV: Purchase Intention } & \multicolumn{3}{c|}{ DV: Forward Intention } \\
\hline 1. IV & Model 1 & Model 2 & Model 3 & Model 1 & Model 2 & Model 3 \\
\hline Relationship Intensity & $.424^{* * *}$ & $.407^{* * *}$ & $.234^{*}$ & $.169^{* * *}$ & $.141^{* * *}$ & -.017 \\
\hline Brand Image & $.340^{* * *}$ & $.333^{* * *}$ & $.617^{* * *}$ & $.299^{* * *}$ & $.332^{* * *}$ & .082 \\
\hline Trust Propensity & $.172^{* * *}$ & $.207^{* * *}$ & .082 & $.119^{\dagger}$ & $.125^{\dagger}$ & $.529^{* * *}$ \\
\hline 2.Moderator & & & & & & \\
\hline Price & & -.080 & -.087 & & -.004 & -.028 \\
\hline 3.Mpderator Effect & & & & & & \\
\hline RI*P & & & .051 & & & .051 \\
\hline BI*P & & &. $.306^{* * *}$ & & & $.348^{* * *}$ \\
\hline ITP*P $^{2}$ & & & .040 & & & $-.464^{* * *}$ \\
\hline $\mathrm{R}^{2}$ & .442 & .440 & .461 & .272 & .295 & .356 \\
\hline Adjusted R & .432 & .426 & .436 & .259 & .276 & .326 \\
\hline F & $43.919^{* * *}$ & $29.522^{* * *}$ & $17.911^{* * *}$ & $20.706^{* * *}$ & $15.684^{* * *}$ & $11.629^{* * *}$ \\
\hline
\end{tabular}

The moderator effects of product type are shown in Tab. 4. Because the product type is categorical variable, we compare the regression coefficient in different groups to test 
the moderator effect. Results in Tab. 4 showed, for search good, brand image has the most effect on purchase $(\beta=0.501, \mathrm{P}<0.001)$ and forward intention $(\beta=0.399, \mathrm{P}<0.001)$; for experience good, relationship intensity is critical for purchase $(\beta=0.516, \mathrm{P}<0.001)$ and forward intention $(\beta=0.195, \mathrm{P}<0.001), \mathrm{H} 5 \mathrm{a} \sim \mathrm{H} 5 \mathrm{~d}$ are supported.

Tab. 4 Moderator Effects of Product Type

\begin{tabular}{|c|c|c|c|c|}
\hline & \multicolumn{2}{|c|}{ DV: Purchase Intention } & \multicolumn{2}{|c|}{ DV: Forward Intention } \\
\hline IV & Search Goods & Experience Goods & Search Goods & Experience Goods \\
\hline Relationship Intensity & $.363^{* * *}$ & $.516^{* * * *}$ & $.218^{* * * *}$ & $195^{* * *}$ \\
\hline Brand Image & $.501^{* * * *}$ & $.202^{* * * *}$ & $.399^{* * * *}$ & $.184^{* * * *}$ \\
\hline Individual Trust Propensity & .093 & $.240^{* * * *}$ & .064 & $.157^{\dagger}$ \\
\hline $\mathrm{N}$ & 70 & 88 & 70 & 88 \\
\hline $\mathrm{R}^{2}$ & .630 & .607 & 477 & .539 \\
\hline Adjusted $\mathrm{R}^{2}$ & .461 & .465 & .342 & .233 \\
\hline $\mathrm{F}$ & $18.780^{* * *}$ & $24.321^{* * *}$ & $11.414^{* * * *}$ & $8.522^{* * * *}$ \\
\hline
\end{tabular}

\section{Conclusions and Implications}

\section{Effects of Relationship Intensity, Brand Image and Individual Trust Propensity on Consumers' Purchase and Forward Intention}

In WeChat marketing, relationship intensity, brand image and individual trust propensity are critical for consumer purchase and forward intention. In our sample, purchase intention in strong relationship group is higher than the weak group, the effect of brand image on forward intention is much stronger, and the effect of individual trust propensity on purchase and forward intention are relatively weak. It means that relationship and brand factors play more important roles in WeChat marketing, but the influence of individual trust propensity is relatively weak. Therefore, the seller should put special emphasis on customer relationship management, improving the relationship quality, and pay more attention to brand building activities, improve consumer's brand perception, to improve the purchase and forward intention.

\section{The Moderate Effect of Product Price}

This study indicated that the price only moderate the effects of band image on purchase and forward intention, as well as the individual trust propensity on forward intention. With the increase of product cost, consumers' purchase decision will be more cautious, they tend to forward the product information with good brand image, rather than purchase directly. Therefore, the sellers who sell affordable products in WeChat friends circle, should put special emphasis on product brand image, and should allocate more marketing resources to customers with higher level of individual trust propensity; otherwise, for the sellers who sell products with higher price in WeChat friends circle, although the brand image promotion cannot bring direct purchase, but can enhance the consumers' willingness to forward, finally have a good reputation effect.

\section{The Moderate Effect of Product Type}

This study indicated, for search good, brand image is the important factors for consumers' purchase and forward intention; for experience good, relationship intensity has more effect on purchase and forward intention. It showed that, when consumers purchase search goods, they obviously reveal the features of rational consumption, when consumers purchase experience good, they are more vulnerable to the relationship 
factors, and the effect of individual trust propensity on purchase and forward intention is enhanced. Therefore, the sellers who sell search good in WeChat friends circle, should put special emphasis on product information clues represented by brand, meanwhile, for experience good, sellers should focus on the relationship maintenance and pay special attention to the higher level of individual trust propensity groups.

\section{Limitations and Future Research}

Due to convenience sampling instead of random and stratified sampling, this study inevitable had limitations in universality. Future research should consider various factors such as age, occupation and income, etc. It also didn't address the issue about the negative effect in WeChat marketing, which should be improved in the future.

\section{Acknowledgement}

This research was financially supported by the Research Foundation of Education Department of Liaoning Province (W2014008); Social Science Foundation of Liaoning Province (L14DGL051); Foundation of Liaoning University (LDQN201422).

\section{References}

[1] Rui-qiang Li, Yong-qiang Li. Will Tie Strength and Relationship Asymmetry Between Two Salespeople Influence Their Unethical Behavior?[J]. Management Review, 2014,26(10):160-172. In Chinese

[2] Tao Wang, Yan-ping Li. The research on referral's influence on consumers' purchase decision in virtual community[J]. Business economics and management, 2007, 193(11): 50-56. In Chinese

[3] Jian-li Zhou, Ai-hua Zhang, Jing Duan. The effect of the strength of social relation on applications usage intention in social network[J]. China Science and Technology Information. Dec.2012:80-82. In Chinese

[4] Chun-jiang Fu, Deng-hua Yuan, Si-ming Luo. Brand's Country-of-origin Stereotypes: Dual Impression and Their Changes [J]. Journal of Psychological Science, 2013, 36(3):606-611. In Chinese

[5] Yi-zhe Chen. The Internet Word of Mouth Clothing Brand: Empirical Research [D]. Xi'an Polytechnic University, 2013. In Chinese

[6] Mei-hui Zhang. The Influence of College Students' Trust Propensity on Perceived Risk in Online Shopping [D]. Jilin University, 2013. In Chinese

[7] Kim KH, Ko E, Graham H, Lee DH, Jung HS, Jeon BJ. Brand equity and purchase intention in fashion products: a cross-cultural study in Asia and Europe [J]. Journal of Global Academy of Marketing Science 2008;18(4):245-276.

[8] Petty, R.E., Cacioppo, J.T. Communication and Persuasion: Central and Peripheral Routes to Persuasion. New York: Springe-Verlag, 1986.

[9] Jun Fan, Dong-qiang Shen, Fan Lin. The Impact of Product Image on Consumer's Purchasing Intentions: Based on Moderating Effects of Product Type [J]. Journal of Marketing Science. Vol. 10 No.4, Dec 2014:97-108. In Chinese 